\title{
EDUCAÇÃO AMBIENTAL COMO INSTRUMENTO DE FORMAÇÃO DO SUJEITO ECOLÓGICO
}

\author{
Mário Yudi Takada, Genivaldo de Souza Santos \\ Universidade do Oeste Paulista - UNOESTE, Pós - Graduação stricto senso em Educação, Presidente Prudente, SP. e- \\ mail: mario.yt@adv.oabsp.org.br
}

\section{RESUMO}

Este trabalho faz parte do projeto O lócus da Ética na Educação Ambiental desenvolvido junto ao Grupo de Pesquisa Instituição Educacional: Gestão e Organização do Programa de Pós-Graduação stricto senso em Educação da Unoeste. Nos últimos anos, podemos observar as inúmeras catástrofes ambientais e alterações climáticas que vem ocorrendo, estes fatos não são por acaso, mas de acordo com parte da comunidade científica, respostas da natureza diante das agressões provocadas pelo homem. Um dos grandes desafios sociais está relacionado à formação educacional intrinsecamente ligada à formação ética e moral, na medida em que a Ética, desde suas origens gregas até os dias atuais, é o campo do saber humano voltado para a ação humana. Assim sendo, será traçado uma visão panorâmica do quadro atual apontando como um dos caminhos necessários à resolução deste problema a Educação Ambiental, no potencial de transformação social em que pese à formação do Sujeito Ecológico. A pesquisa possui uma abordagem qualitativa de cunho fenomenológico e base hermenêutica, cujo procedimento utilizados foram o levantamento bibliográfico e documental.

Palavras-chave: Educação Ambiental, Ética, Sujeito Ecológico.

\section{ENVIRONMENTAL EDUCATION AS A TOOL OF TRAINING SUBJECT OF ECOLOGICAL}

\begin{abstract}
This work is part of the project The locus of Ethics in Environmental Education developed by the Research Group of Educational Institution: Management and Organization of the Graduate Program in Education strict sense of Unoeste. In recent years, we can observe the numerous environmental disasters and climate change that has occurred, these facts are not by chance, but according to the scientific community, the nature of the responses to aggression manmade. One of the major challenges facing society is related to the educational background, intrinsically linked to ethics and moral education insofar as ethics, from its Greek origins to the present day, is the field of human knowledge toward human action. Therefore, an overview will be drawn from the current frame pointing to one of the paths needed to resolve this problem Environmental Education, the potential for social transformation in spite of the formation of the Ecological Subject. The study has a qualitative approach and hermeneutic phenomenological nature base, whose procedure used were the bibliographic and documentary.
\end{abstract}

Keywords: Environmental Education, Ethics, Ecological Subject. 


\section{INTRODUÇÃO}

A temática ambiental atualmente é um dos assuntos de maior relevância na sociedade, a forma de vida existente no planeta Terra está intrinsecamente ligada ao meio ambiente, esta que é essencial para sobrevivência e evolução da sociedade. Os problemas ambientais são de total e indiscutivelmente responsabilidade do ser humano, assim, a ética deve se preocupar com o estilo de vida atual do homem lembrando sempre da vulnerabilidade da natureza (JONAS, 1997). Lutzenberger (1983, p.37) aduz que "estamos agindo como se fôssemos a última geração e a única espécie que tem direito à vida. Nossa ética que não abarca os demais seres, não inclui sequer os nossos filhos". O grande equívoco da humanidade é isolar o homem do restante da natureza, sendo que ambos devem ser vistos em conjunto. O homem é um ser capaz de saber de suas responsabilidades e conseqüências de seus atos, o seu trato com o mundo irá determinar o futuro de nossa existência (JONAS, 2005).

Nos tempos de outrora o meio ambiente era contemplado pelo ser humano com mais respeito. Os pesquisadores desta época investigavam a intenção nos fenômenos naturais, levando em consideração questões relativas a Deus, à alma e a ética. A cosmovisão de estar inserido dentro de um sistema orgânico, entrelaçado e cheio de vida, em que o ser humano não disponibilizava de tanto conhecimento e recurso tecnológico, tornava a natureza desconhecida, sendo um poder superior que deveria ser respeitado (CAPRA, 2003).

A crise ambiental enfrentada nos dias de hoje tem suas origens no séc. XVII, neste período houve grande influência da Revolução Científica transformando o modo em que o mundo era visto. Este novo paradigma apresentado fez com que o ser humano enxergasse as coisas de maneira racional, buscando explicações para o mundo. Os mistérios da natureza começam a ser desvendados com o propósito de enriquecer o ser humano como homo faber ${ }^{1}$ (PELIZZOLI, 2002).

Nesta época, com o avanço científico e a noção de progresso, a gana pelo conhecimento em virtude da razão soberana, embora tenha contribuído intelectualmente para o ser humano, converteu - se em um racionalismo extremado, determinando o destino de todos os seres vivos. A razão começa a se tornar um instrumento onde o ser humano para de buscar a ciências como meio de acessar o conhecimento verdadeiro, para se tornar um instrumento de poder.

Neste sentido Pelizzoli (2002, p.08) aduz: 
Veja-se que é desde aí que a Razão, alardeada como motivo de emancipação e felicidade, degenera em Razão instrumental, termo muito bem trabalhado pela Escola de Frankfurt, para mostrar como a racionalidade vigente se torna calculista, algo desumanizadora

e
determinada exclusivamente pelos processos técnicos e utilitaristas de um Sistema que nos escapa.

Este desequilíbrio na relação do homem com o meio ambiente compromete a qualidade de vida das pessoas, forçando estas a se adaptarem com o meio e conviverem com esta realidade crítica. $\mathrm{O}$ resultado deste quadro é o aumento da proliferação de doenças, exposição da população a pobreza, escassez dos alimentos, falta de água e o desaparecimento das paisagens naturais, tudo isto, exemplifica a insustentabilidade do modelo civilizatório do nosso planeta.

Em trabalho recente, pesquisadores indicaram que a humanidade esta vivenciando a sexta era da extinção em massa do nosso planeta, sendo o principal agente causador "o homem". Os pesquisadores argumentam que todas as espécies de vida algum dia irá se extinguir, no entanto, com a presença humana esta extinção tem acelerado cerca de mil vezes se comparado a forma de extinção natural das espécies (DIRZO et al., 2014).

Atualmente, muito tem se falado de conservação do meio ambiente, todavia ainda não se criou o respeito e a consciência ambiental, sendo que esta crise vivenciada possui uma grande relação com a educação, na qual existem inúmeros desafios e obstáculos.

A educação ambiental deveria encontrar meios para ensinar as novas gerações a devida consciência e mentalidade conservacionista, facilitando à implementação de políticas públicas voltadas a utilização dos recursos naturais de maneira sustentável. Ainda, uma nova geração seria muito mais insuscetível e resistente as tentações oriundas do modelo civilizatório atual, lembrando que, para que isso não ocorra, a educação ambiental deveria prever a vulnerabilidade das pessoas. Sendo assim, trata-se de uma educação totalmente voltada para a formação do sujeito ecológico.

\section{METODOLOGIA}

A presente pesquisa se insere em uma abordagem qualitativa de cunho fenomenológico e base hermenêutica, cujos procedimentos utilizados foram o levantamento bibliográfico e o documental. 


\section{DISCUSSÃO}

Na Constituição Federal de 1988, o legislador trouxe em seu corpo, direitos e garantias fundamentais inerentes ao homem. Neste contexto, devemos observar que o direito a educação esta inserida nos direitos fundamentais de segunda dimensão, sendo um direito conquistado a todos ao longo dos tempos, sem distinção de qualquer natureza, estando alicerçado no art. 6, da Constituição Federal de 1988.

No contexto da Filosofia do Direito, Mônica Tereza Mansur Linhares (2010, p.59), conceitua educação como:

Uma das atividades mais elementares do homem: ela se inscreve no princípio fundador e formador do desenvolvimento dos indivíduos e da sociedade. Esse sentido indica que a educação é um princípio universal, descrito como fundamento antropológico que liga o indivíduo à sua espécie, à sociedade, à linguagem e à cultura. Movimento esse que designa um processo que vincula um sujeito ao seu meio ambiente, a um sistema de sociedade, de cultura e de valores, onde tomam lugar, muito especial as instituições de ensino.

No mesmo sentido, o direito a um meio ambiente equilibrado faz parte dos direitos fundamentais de terceira dimensão.
A Constituição Federal de 1988, indica um amplo destaque a proteção ao meio ambiente, encontrando arrimo em um vasto leque de artigos, como exemplos o $5^{\circ}$, LXXIII; $20^{\circ}$, II a XI, e $\S 1^{\circ}$, entre outros.

O Estado e a coletividade possuem o dever de preservar o meio ambiente, haja vista ser um bem de uso comum do povo, ou seja, é um bem de fruição geral da coletividade, de natureza difusa, uma res omnium (coisa de todos) (LENZA, 2011).

Imperiosamente cabe destacar que a Constituição Federal de 1988, estabeleceu como princípios fundamentais a educação e o meio ambiente ecologicamente equilibrado com a intenção de que tenha dois dos fundamentos da República Federativa do Brasil respeitado, que são a efetivação do princípio da dignidade da pessoa humana e cidadania (art. $1^{\circ}$, II e III, da CF/88).

O princípio da dignidade da pessoa humana é regra matriz dos direitos fundamentais, pois, todas as atitudes devem ser voltadas em prol do ser humano, inclusive, deve servir para orientar as necessárias soluções de conflitos de direitos. Assim, a educação garante ao cidadão uma vida digna, no sentido de aprendizagem, cultura, ética, moral, entre outros, e o meio ambiente garante a vida das presentes e futuras gerações, tudo isso, visando garantir e promover a cidadania (MORAES, 2008). 
Neste cenário, fazendo-se uma fusão desses dois direitos fundamentais, surge a educação ambiental com fundamento na preocupação social, frente à qualidade de vida da presente geração e da existência das futuras gerações. A educação ambiental está entre as alternativas que visam arquitetar novos costumes de relacionamento do homem com o meio ambiente, visando à formação do Sujeito Ecológico.

Interpretando 0 art. $1^{\circ}$, da lei 9.795/99, na qual traz uma definição para Educação Ambiental, conclui - se que esta é formada por uma gama de processos, de cunho social, político, cultural econômico, filosófico, entre outros, e não só relacionados à ecologia. "Estes processos visam a conscientizar e, acima de tudo, mobilizar a todos, pessoas físicas e jurídicas, no rumo da conservação do meio ambiente. O conceito relaciona, dessa forma, a educação ambiental com a sustentabilidade" (DILL, 2008, p.85).

Carlos Frederico Bernardo Loureiro (2000, p.69), conceitua a educação ambiental, aduzind o o seguinte:

A educação ambiental é uma práxis educativa e social que tem por finalidade a construção de valores, conceitos, habilidades e atitudes que possibilitem 0 entendimento da realidade de vida e a atuação lúcida e responsável de atores sociais individuais e coletivos no ambiente.
Nesse sentido, contribui para a tentativa de implementação de um padrão civilizacional e societário distinto do vigente, pautado numa nova ética da relação sociedade-natureza.

Após a tutela constitucional e a referida lei, o processo de educação ambiental adquire uma dimensão transcendental, sendo que, se torna uma das finalidades do Estado enquanto representação da própria sociedade como decorrência de um pacto social. Vale dizer, a proteção conferida pela Constituição Federal à educação ambiental é uma exigência nacional que aglomera perspectivas diferentes, todavia complementares, trata-se de exigência social e natural (MILARÉ, 2011, p.205).

A educação ambiental se incorporou como um direito do cidadão, estando intimamente conectado aos direitos e deveres constitucionais da cidadania. Nestes termos, a educação ambiental se mostra como ferramenta necessária para transformar a visão da sociedade, para que esta adote um estilo de vida ecológico.

Fritjof Capra (2003), em seu livro $A$ teia da vida, traz importantes declarações sob a alfabetização ecológica, e como podemos nos espelhar no ecossistema, no sentido de viver de maneira sustentável. Aduz que, em bilhões de anos de evolução 
"os ecossistemas do planeta têm se organizado de maneiras sutis e complexas, a fim de maximizar a sustentabilidade. Essa sabedoria da natureza é a essência da eco alfabetização" (CAPRA, 2003, p.231). Ainda, o referido autor diz que "todos os membros de uma comunidade ecológica estão interligados numa vasta e intrincada rede de relações, a teia da vida." (CAPRA, 2003, p.231).

A relevância da temática deve ser observada como forma de exterminar a cultura do desperdício. Esta que se enraizou na cultura brasileira e de vários outros povos do planeta, um consumismo exagerado, o que nos leva a uma grande demanda na fabricação de produtos industrializados, uma verdadeira economia sem ética. A cultura do descartável está tornando as pessoas insensíveis ao meio ambiente, incluído também o excesso de desperdício de alimentos, apesar da pobreza em vários locais do mundo, em que faltam alimentos.

Devemos destacar que o modo de ser de cada ser humano no mundo, muitas vezes é visto como algo individual, transparecendo que o relacionamento do individuo com 0 mundo são distantes não havendo uma ligação entre eles. No entanto, devemos acabar com este modo de visão, pois, o homem faz parte do mundo, e ambos devem ser entendidos como um todo, pensados de forma inseparável. Neste sentido, Isabel
Cristina de Carvalho Moura (2007, p. 31) aduz:

A busca de superação destas dicotomias que constituem a divisão disciplinar de nossas áreas do conhecimento, remete inevitavelmente para a interdisciplinaridade. Por isso trata-se de falar desde uma psicologia - afinal interdisciplinaridade não é a dissolução das disciplinas - mas de uma psicologia em dialogo com outras áreas do saber, particularmente dentro das humanidades. Com isto, rompe-se com uma psicologia essencialista que supõe uma esfera da vida pré-social ou précultural que interage sem se confundir com a esfera social e cultural. Parece-nos mais produtivo pensar 0 fenômeno humano como desde sempre localizado no mundo, num ambiente cultural e histórico. Assim, quando se torna possível ver o mundo abandonando as dicotomias, vislumbra-se o sujeito humano e os fatos sociais como um fenômeno simultaneamente social e individual, subjetivo e objetivo, psíquico e biológico, cultural e natural. Neste sentido, tomando o humano como um ser no mundo, a vida pessoal não pode mais ser tomada apenas um acontecimento particular, mas é desde sempre, constituída pelos elementos culturais e pela historicidade. 
Compreendendo esta relação de cada ser humano no mundo e o seu modo de ser específico, vislumbramos diversos estilos de vida, dentre eles o ecológico. Este sujeito almeja um ideal ecológico, um caminho a ser traçado e seguido, que servirá de orientação nas decisões e escolhas do seu dia a dia. Não podemos esquecer que estes sujeitos não conseguiram ter um estilo de vida totalmente ecológico diante dos obstáculos impostos pela atual sociedade, haja vista que os princípios ecológicos não são preponderantes em nossa população e são ignorados pelas políticas públicas e outras iniciativas (CARVALHO, 2007).

\section{CONCLUSÃO}

O sistema educacional brasileiro vem tratando de maneira inadequada a formação de cidadãos detentores e conscientes de suas responsabilidades sociais, privilegiando processos formativos que visam à produção e o consumo. As políticas públicas educacionais estão se preocupando em obter resultados, no sentido da educação básica mínima. As escolas tem se preocupado em formar cidadãos para o mercado de trabalho, mas esquecem que sem um meio ambiente adequado não existirá o trabalho em si, por isso devemos repensar o tipo de educação que esta sendo ofertada em nosso sistema.

Diante disso, podemos concluir que a Educação Ambiental é uma ferramenta necessária para uma transformação na mentalidade da sociedade planetária, criando um modo de vida sustentável, formando o sujeito ecológico.

\section{REFERÊNCIAS}

BRASIL. Constituição (1988). Constituição da República Federativa do Brasil. Brasília: Senado Federal, 1988. Disponível em: <http://www.planalto.gov.br/ccivil_03/consti tuicao/constituicao.htm>. Acesso em: 20 jul. 2014.

BRASIL. Lei 9795, de 27 de abril de 1999. Dispõe sobre a educação ambiental, institui a Política Nacional de Educação Ambiental e dá outras providências. Diário Oficial da União, Brasília, DF., 27 de abril de 1999. Disponível em: <http://www.planalto.gov.br/ccivil_03/leis/19 795.htm>. Acesso em: 20 jul. 2014.

CAPRA, F.A teia da vida: uma nova compreensão científica dos sistemas vivos. 8 . ed. São Paulo: Cultrix, 2003. 256 p.

CARVALHO, I. C. M. Subjetividade e sujeito ecológico: contribuições da psicologia social para a educação ambiental. In: GUERRA, A. F.; TAGLIEBER, E. (Org.). Educação ambiental: fundamentos, práticas e desafios. 1. ed. Itajai: UNIVALI, 2007. p.29-36.

DILL, M. A. Educação ambiental crítica: a formação da consciência ecológica. Porto Alegre: Nuria Fabris, 2008. 142 p.

DIRZO, R. et al. Defaunation in the Anthropocene. Science, v.345, n.6195, p.405, $2014 . \quad$ Disponível em: $<10.1126 /$ science.1251817>. Acesso em: 28 jul. 2014.

HOMO FABER. In: Dicionário Priberam da Língua Portuguesa. 2008-2013. Disponível 
em: <http://www.priberam.pt/dlpo/homo\%2 Ofaber>. Acesso em: 20 jul. 2014.

JONAS, H. $O$ princípio responsabilidade: ensaio de uma ética para uma civilização tecnológica. Rio de Janeiro: PUC Rio, 2005.

JONAS, H. Técnica, medicina y ética. Barcelona: Paidós, 1997.

LENZA, P. Direito constitucional esquematizado. 15. ed. São Paulo: Saraiva, 2011. 1196 p.

LINHARES, M. T. M. L. Ensino jurídico: educação, currículo e diretrizes curriculares no curso de direito. São Paulo: Iglu, 2010.

LOUREIRO, C. F. B. Educação ambiental e movimentos sociais na construção da cidadania ecológica e planetária._In: EDUCAÇÃO ambiental: repensando o espaço da cidadania. 2. ed. São Paulo: Cortez, 2000. $255 \mathrm{p}$.

LUTZENBERGER, J. Fim do Futuro? Manifesto Ecológico Brasileiro. 3.ed. Porto Alegre: Movimento, UFRGS, 1983.

MILARÉ, É. Direito do ambiente: doutrina, prática, jurisprudência, glossário. 7. ed. São Paulo: Revista dos Tribunais, 2011. 1280 p.

MORAES, A. Direito constitucional. 23. ed. São Paulo: Atlas, 2008. 900 p.

PELIZZOLI, M. L. Correntes da ética ambiental. Petrópolis: Vozes, 2002. 121 p.

Recebido para publicação em 12/08/2014

Revisado em 28/08/2014

Aceito em 15/09/2014 